Supporting Information

\title{
Evaluation of Impurities in Aluminum Anodes for Al-air Batteries
}

\author{
Jianming Ren, Chaopeng Fu, ${ }^{*}$ Qing Dong, Min Jiang, Anping Dong, 'Guoliang Zhu, \\ Jiao Zhang, Baode Sun
}

School of Materials Science and Engineering, Shanghai Jiao Tong University, 800 Dongchuan RD. Minhang District, Shanghai 200240, P. R. China

${ }^{*}$ Corresponding authors:

chaopengfu@sjtu.edu.cn (Chaopeng Fu)

apdong@sjtu.edu.cn (Anping Dong)

Number of pages: 5

Number of figures: 1

Number of tables: 1 


\section{Preparation of the air cathode:}

For the cathode preparation, the catalyst layer was prepared by a mixture of $\mathrm{MnO}_{2}$ nanoparticles, carbon black (Vulcan XC-72) and poly (tetrafluoroethylene) (60 wt\% emulsion) with a mass ratio of 20:60:20, which was stirred in ethanol and rolled into a film. The obtained film was then pressed onto a nickel foam. The gas diffusion layer was prepared by a mixture of carbon black (Vulcan XC-72) and poly (tetrafluoroethylene) (60 wt\% emulsion) with a mass ratio of 40:60. The gas diffusion layer was then pressed onto the other side the nickel foam under a pressure of $40 \mathrm{MPa}$ for 5 min to obtain the air cathode. 


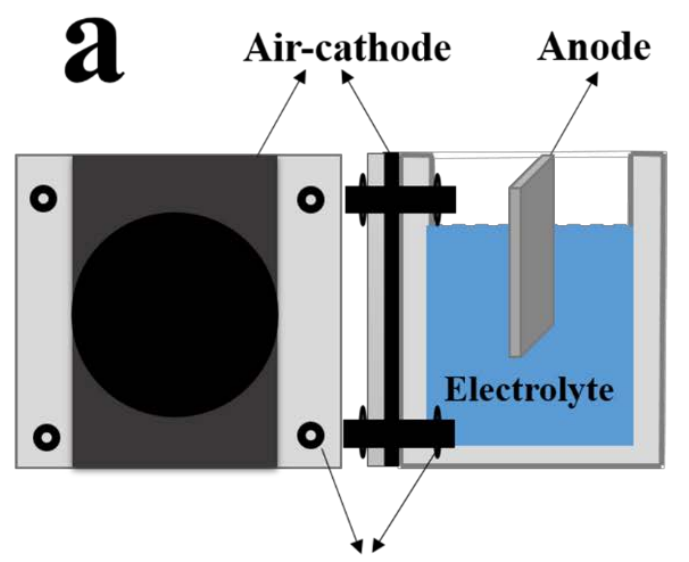

b

Screws

Figure S1 (a) The scheme and (b) a real picture of the house-made Al-air battery. 
We have compared the open circuit voltage (OCV) of the $\mathrm{Al}$ anodes with various purities to the previous literature mentioned in the introduction, and the result is shown in Table S1 (Supporting information). The OCV is lower than those with $\mathrm{Al}$ alloy anodes, but higher than those with pure $\mathrm{Al}$ anodes in literature.

Table S1 Comparison of open circuit voltages of the Al-air batteries with various $\mathrm{Al}$ anodes in the introduction.

\begin{tabular}{|c|c|c|c|c|}
\hline No & Al anode & $\operatorname{OCV}(\mathrm{V})$ & Electrolyte & Reference \\
\hline 1 & $5 \mathrm{~N} \mathrm{Al}$ & 1.591 & $4 \mathrm{M} \mathrm{NaOH}$ & $\begin{array}{c}\text { J. Power } \\
\text { Sources } \\
\text { 2015, 284, } \\
409\end{array}$ \\
\hline \multirow{5}{*}{2} & $5 \mathrm{~N} \mathrm{Al}$ & 1.752 & \multirow{5}{*}{$4 \mathrm{M} \mathrm{KOH}$} & \multirow{5}{*}{$\begin{array}{l}\text { J. Power } \\
\text { Sources } \\
\text { 2019, 425, } \\
\text { 186-194. }\end{array}$} \\
\hline & $\mathrm{Al}-0.02 \mathrm{Sb}$ & 1.828 & & \\
\hline & $\mathrm{Al}-0.06 \mathrm{Sb}$ & 1.881 & & \\
\hline & Al-0.18Sb & 1.895 & & \\
\hline & Al-0.36Sb & 1.912 & & \\
\hline \multirow[b]{3}{*}{3} & $\mathrm{Al}-0.1 \mathrm{Sn}$ & 1.78 & \multirow[b]{3}{*}{$4 \mathrm{M} \mathrm{KOH}$} & \multirow{3}{*}{$\begin{array}{l}\text { J. Alloys } \\
\text { Compd. } \\
\text { 2019, 808, } \\
151708 .\end{array}$} \\
\hline & Al-1.0Mg & 1.89 & & \\
\hline & Al-1.0Mg-0.1Sn & 1.94 & & \\
\hline
\end{tabular}




\begin{tabular}{|c|c|c|c|c|}
\hline \multirow{3}{*}{4} & 2N5 Al & 1.52 & \multirow{3}{*}{$4 \mathrm{M} \mathrm{NaOH}$} & J. Power \\
\hline & \multirow[t]{2}{*}{$4 \mathrm{~N} \mathrm{Al}$} & \multirow[t]{2}{*}{1.64} & & $\begin{array}{c}\text { Sources } \\
\text { 2015, 277, }\end{array}$ \\
\hline & & & & $370-378$ \\
\hline \multirow{5}{*}{5} & 2N8 Al & 1.47 & \multirow{5}{*}{$4 \mathrm{M} \mathrm{KOH}$} & \multirow{5}{*}{ In this work } \\
\hline & 3N6 Al & 1.73 & & \\
\hline & $3 \mathrm{~N} 8 \mathrm{Al}$ & 1.56 & & \\
\hline & 4N6 Al & 1.61 & & \\
\hline & $5 \mathrm{~N} \mathrm{Al}$ & 1.87 & & \\
\hline
\end{tabular}

